\title{
The Effectiveness of Fine-Needle Aspiration Conducted by The Otolaryngologists
}

\author{
Ju Hyung Jeong, Bon Min Koo, Hyuk Ki Cho, Soon Yong Han, and Chang Ki Yeo \\ Department of Otorhinolaryngology, School of Medicine, Keimyung University, Daegu, Korea
}

\section{두경부 영역에서 시행하는 세침흡인검사의 효용성 연구}

정주형 · 구본민 · 조혁기 · 한순용 · 여창기

계명대학교 의과대학 이비인후과학교실

\author{
Received July 16, 2016 \\ Revised October 4, 2016 \\ Accepted October 6, 2016 \\ Address for correspondence \\ Chang Ki Yeo, MD, PhD \\ Department of Otorhinolaryngology, \\ School of Medicine, \\ Keimyung University, \\ 56 Dalseong-ro, Jung-gu, \\ Daegu 41931, Korea \\ Tel $+82-53-250-7711$ \\ Fax $+82-53-256-0325$ \\ E-mail ckyeo@dsmc.or.kr
}

Background and Objectives To investigate the effectiveness of fine needle aspiration (FNA) conducted by the otolaryngologists, we compared the ultrasound (US)-guided FNA results conducted by a radiologist (RD-US), the US-guided FNA results (ENT-US), and the palpation guided FNA results (ENT-palpation) conducted by an otolaryngologist.

Subjects and Method 1646 patients who underwent FNA were classified according to the site and periods of investigation (2007-2015), and their sampling adequacy was retrospectively reviewed. They were also divided into three groups (ENT-US, ENT-palpation, and RD-US); each group was then investigated for sampling adequacy. Results of further surgical excisional biopsy were compared with the those of the FNA results to investigate the diagnostic accuracy of all three groups.

Results The sampling adequacy identified by the groups showed the result of ENT-US at $87.9 \%$, ENT-palpation at $87.1 \%$ and RD-US at $91.3 \%$. The periodical inadequacy rate failed to show any significant differences between the groups. The sensitivity of ENT-palpation was lower than other two groups. Diagnostic accuracy identified by the groups showed the result of ENT-US at $95.2 \%$, ENT-palpation at $93.6 \%$, and RD-US at $97.4 \%$.

Conclusion FNA performed by otolaryngologists demonstrates the effectiveness of diagnosis and treatment, and that doing so would improve economic efficiency. Therefore, it is recommended that well-trained otolaryngologists conduct FNA actively.

Korean J Otorhinolaryngol-Head Neck Surg 2016;59(12):843-7

Key Words Adequacy · Diagnostic accuracy · Diagnostic ultrasound · Fine-needle aspiration $\cdot$ Palpations.

\section{서 론}

세침흡인검사는 갑상선, 침샘, 림프절 등을 포함한 두경부 영역에서 다양하게 생기는 양성 및 악성 종괴를 진단하는 데 있어 널리 이용되고 있는 진단도구이다. ${ }^{1-3)}$ 일반적으로 외경 이 $0.7 \mathrm{~mm}$ 정도인 22gauge의 바늘을 이용하기 때문에, 시 술 중에 동맥을 천자한 경우에도 압박을 통해 쉽게 지혈되 고, 절개 생검이 곤란한 상황에서 간편하게 시술을 할 수 있 다는 등의 장점이 있다.
영상학적 진단 기술의 발달로 초음파 기기를 사용하여 종 괴의 정확한 위치와 크기를 평가한 뒤 세침흡인검사를 시행 하는 경우가 많아지고 있다. ${ }^{4)}$ 전통적으로 영상의학과에 검사 를 의뢰하는 경우가 많았는데, 이 경우 환자의 병원 방문 횟 수가 증가하고, 이에 따른 경제적 비용의 증가와 함께 진단 및 치료가 지연되는 문제가 생기는 단점이 있었다.5,6) 이를 해 결하기 위해 외래 진료실에서 진료와 동시에 세침흡인세포검 사를 할 수 있는 체계를 구축하는 것이 필요하다는 의견이 제 시되었다. ${ }^{1,4,6,7)}$ 갑상선을 대상으로 시행한 초음파 유도하 세침 
흡인검사에서 임상의가 시행한 결과가 영상의가 시행한 결과 에 비해 차이가 없다는 이전의 여러 연구결과가 있었으며, 1,4,6,8,9) 이를 토대로 본 연구에서는 갑상선뿐만 아니라, 침샘, 림프절 등을 포함한 다양한 두경부 영역에서 시행한 세침흡인검사 결과를 바탕으로 표본의 적절성과 진단의 정확도를 파악, 비 교해 보고자 한다.

\section{대상 및 방법}

\section{대 상}

본 조사는 2007년 1월 1일부터 2015년 7월 31일까지 계명 대학교 동산의료원 이비인후과와 영상의학과에서 세침흡인 검사를 이용하여 진단 받은 1646명(갑상선 585예, 침샘 209 예, 림프절 753예, 기타 99예)을 추후 시행한 외과적 절제 생검 결과와 대조하여 후향적으로 비교 분석하였다. 남자 597명, 여 자 1049명으로 남녀 비율 1대 1.76으로 여자가 많았으며, 평균 나이는 50.83 18.54 세였으며, 2세부터 94세까지 다양한 연령 분포를 보였다.

세침흡인검사를 시행한 부서에 따라 이비인후과군과 영상의 학과군(ultrasound guided fine-needle aspiration conducted by a radiologist, RD-US)으로 나누었으며, 그 중 이비인후과 군을 초음파를 사용하여 세침흡인검사를 시행한 군(ultrasound guided fine-needle aspiration conducted by an otolaryngologist, ENT-US)과 촉진하에 시행한 군(palpation guided fine-needle aspiration conducted by an otolaryngologist, ENT-palpation)으로 나누어 총 3집단으로 분류를 하였다.

또한 시행한 부위에 따라 갑상선, 침샘, 림프절, 기타 총 4집 단으로 분류하였으며, 경험에 따른 적절성 변화를 확인하기 위해 기간에 따른 표본 적절성 변화를 3개년씩 묶어 각 그룹 간 비적절성 비율을 비교하였다. 추후 외과적 절제 생검을 시 행 받은 환자는 총 415명(ENT-US 111예, ENT-palpation 156예, RD-US 148예)으로 확인되었다.

\section{세침흡인검사}

이비인후과에서 시행한 세침흡인검사는 외래진료실에서 시행되었다. 환자들은 부위에 따라 자세를 변화시켰는데 충 분히 경부를 신전시켜 병변이 잘 노출되도록 하였으며, 오른 손잡이 술자는 주로 병변이 바라보이는 정면에 위치하였다. 이비인후과의 경우 육안으로 보고 먼저 초음파를 적용하였 고 너무 이동성이 심한 경우에는 촉진하에 세침흡인검사를 시행하였다. 이비인후과에서 사용한 초음파기구는 $5 \sim 9 \mathrm{MHz}$ linear array Ultrasound Transducer(Medison, Seoul, Ko- rea)를 가진 HD3 Diagnostic Ultrasound System(Philips U1trasound, Bothell, WA, USA)을 사용하였고 영상의학과에서 는 Acuson Sequoia 512 Diagnostic Ultrasound System(Simens Medical Solution, Mountain View, CA, USA)을 사용 하였다. 이비인후과에서는 교수, 전임의, 전공의에 의해 시행된 것과는 달리 영상의학과에서 시행한 세침흡인검사는 담당 교 수 한 사람에 의해 시행되었다. 세침흡인검사는 Cameco syringe holder에 23gauge 바늘이 달린 $10 \mathrm{cc}$ 주사기를 장착하 여 동일한 부위에 각 2 회씩 시행하였다. 초음파 유도하에 세 침흡인검사를 시행하는 경우, 화면에서 바늘이 종괴 내부로 진입하는 모습을 확인한 뒤, 종괴 내부를 2 3번 통과하거나, 음압을 걸어 바늘에 세포가 채취될 때까지 시행하였다. 이후 주사기 내의 조직을 슬라이드 위에 압출시켜 세포가 파괴되 지 않도록 주의하면서 도말하였으며, 도말한 후에는 즉시 세 포고정액(95\% ethanol)으로 고정하여 병리학적 검사를 의뢰 하였다. 병리학적 검사에는 일반적으로 hematoxylin-eosin 염색, Papanicolaou 염색, Giemsa 염색, periodic acid-schiff (PAS) 염색, acid-fast bacillus(AFB) 염색들이 포함되었으며, 임상적으로 필요할 경우 tuberculosis-polymerase chain reaction(Tb-PCR) 검사도 같이 시행하였다.

\section{결과분석}

초음파 유도하 이비인후과(ENT-US), 촉진하 이비인후과 (ENT-palpation), 그리고 초음파 유도하 영상의학과(RD-US) 의 3집단으로 분류하여 비교하였다. 세침흡인검사결과 검체 의 적절성은 갑상선의 경우 대한 갑상선학회 갑상선결절 및 암진료권고안 개정안(2010)에 따라 보존이 잘된 10개 이상의 여포세포로 이루어진 세포군집이 6개 이상 보이는 것으로 정 의하였고 다른 검체들의 경우 병리과의에 의해 조직학적 satisfactory로 결정된 조직검사로 정의하였다.

진단 정확도 분석에 있어 세침흡인검사의 조직검사상 inflammation, benign cyst, 그리고 그 외 benign 병변들을 Benign으로 suspicious for malignancy, malignant 병변들을 Malignant로 정의하였으며 모호한 병리 결과의 경우 병리과 의에 의한 주석 및 논의를 통해 분류를 확인하였다.

추후 외과적 절제 생검을 시행 받은 예의 세침흡인검사결 과와 조직검사 결과를 비교하여 민감도, 특이도, 양성 예측도, 음성 예측도, 그리고 진단 정확도를 분석하였다. 데이터는 PASW Statistics 18(IBM SPSS, Armonk, NY, USA)을 이용 하여 분석하였다. 집단 간 변수의 연관성의 유의성을 통계적 으로 검정하기 위한 교차분석으로는 Pearson's chi-square test 또는 Fisher's exact test를 사용하였으며, 0.05 미만의 $p$ value를 통계적으로 유의한 것으로 간주하였다. 


\section{결 과}

\section{부위에 따른 분포 및 표본 비적절성}

집단별 표본의 비적절성은 부위에 따라 차이를 보였다 (Table 1). 초음파 유도하 이비인후과군에서는 림프절이 $6.6 \%$ 로 다른 부위에 비해 낮은 비적절성 비율을 보였다. 촉 진하 이비인후과군에서는 침샘의 비적절성 비율이 $8.0 \%$ 로 다른 부위에 비해 낮은 것으로 확인되었다. 영상의학과에서 시행한 초음파 유도하 세침흡인검사결과는 갑상선, 침샘, 림 프절이 비슷한 비적절성 비율이 관찰되는 가운데, 림프절이 $6.1 \%$ 로 가장 낮은 비적절성 비율을 보였다. 세 집단 모두에서 갑상선이 침샘과 림프절에 비해 검체의 비적절성 비율이 높 게 관찰됨을 알 수 있었다. 갑상선의 특성 및 술자의 경험으로 인해 초음파 유도하 이비인후과군과 초음파 유도하 영상의 학과군의 갑상선에 대한 비적절성 비율이 차이를 보였다.

\section{집단 간 표본 적절성 비교}

세 집단 간의 표본 적절성을 비교했을 때, 초음파 유도하 이 비인후과군이 $87.9 \%$, 촉진하 이비인후과군이 $87.1 \%$, 초음파 유도하 영상의학과군이 $91.3 \%$ 로 영상의학과에서 시행한 결과 가 가장 높게 관찰되었다 $(p=0.044)$ (Table 2). 이비인후과 내에 서 초음파 유도하군과 촉진하군의 결과를 비교했을 때에는 서로 유의한 차이가 없었다 $(p=0.707)$.

\section{기간에 따른 표본 적절성 변화}

2007년에서 2015년까지 3개년씩 묶어서 비교한 각 집단의 기간별 비적절성 비율은 유의할 만한 차이를 보이지 않았다 (Table 3).

\section{집단별 세침흡인검사 결과분석}

세 집단에서 추후 외과적 절제 생검을 시행한 경우는 모두

Table 1. Inadequacy sampling rates categorized by organ

\begin{tabular}{lccccc}
\hline & Thyroid, $\mathrm{n}(\%)$ & Salivary gland, $\mathrm{n}(\%)$ & Lymph node, $\mathrm{n}(\%)$ & Others*, $\mathrm{n}(\%)$ & Overall, $\mathrm{n}(\%)$ \\
\hline ENT-US & $24 / 130(18.5)$ & $8 / 71(11.3)$ & $14 / 213(6.6)$ & $6 / 16(37.5)$ & $52 / 430(12.1)$ \\
ENT-palpation & $3 / 7(42.9)$ & $7 / 87(8.0)$ & $40 / 309(12.9)$ & $11 / 69(15.9)$ & $61 / 472(12.9)$ \\
RD-US & $44 / 448(9.8)$ & $4 / 51(7.8)$ & $14 / 231(6.1)$ & $3 / 14(21.4)$ & $65 / 744(8.7)$ \\
p-value & 0.001 & 0.734 & 0.007 & 0.158 & 0.044 \\
\hline
\end{tabular}

*others (benign neck mass, dermoid cyst, thyroglossal duct cyst, lipoma etc.). ENT-US: ultrasound guided fine-needle aspiration conducted by an otolaryngologist, ENT-palpation: palpation guided fine-needle aspiration conducted by an otolaryngologist, RD-US: ultrasound guided fine-needle aspiration conducted by a radiologist

Table 2. Sample adequacy rate

\begin{tabular}{lccc}
\hline & ENT-US, $\mathrm{n}(\%)(\mathrm{n}=430)$ & ENT-palpation, $\mathrm{n}(\%)(\mathrm{n}=472)$ & RD-US, $\mathrm{n}(\%)(\mathrm{n}=744)$ \\
\hline Adequate specimen & $378(87.9)$ & $411(87.1)$ & $679(91.3)$ \\
Inadequate specimen & $52(12.1)$ & $61(12.9)$ & $65(8.7)$
\end{tabular}

ENT-US: ultrasound guided fine-needle aspiration conducted by an otolaryngologist, ENT-palpation: palpation guided fine-needle aspiration conducted by an otolaryngologist, RD-US: ultrasound guided fine-needle aspiration conducted by a radiologist

Table 3. Inadequacy sampling rates during the study periods (2007-2015)

\begin{tabular}{lccc}
\hline & $2007-2009, \mathrm{n}(\%)$ & $2010-2012, \mathrm{n}(\%)$ & $2013-2015, \mathrm{n}(\%)$ \\
\hline ENT-US & $3 / 26(11.5)$ & $6 / 55(10.9)$ & $43 / 349(12.3)$ \\
ENT-palpation & $0 / 2(0.0)$ & $17 / 124(13.7)$ & $44 / 346(12.7)$ \\
RD-US & $20 / 253(7.9)$ & $28 / 322(8.7)$ & $17 / 169(10.1)$ \\
p-value & 0.545 & 0.287 & 0.670 \\
\hline
\end{tabular}

ENT-US: ultrasound guided fine-needle aspiration conducted by an otolaryngologist, ENT-palpation: palpation guided fine-needle aspiration conducted by an otolaryngologist, RD-US: ultrasound guided fine-needle aspiration conducted by a radiologist

Table 4. Diagnostic results of fine-needle aspiration cytology for each groups $(n=286)$

\begin{tabular}{lccc}
\hline & ENT-US (\%) $(n=62)$ & ENT-palpation $(\%)(n=110)$ & RD-US (\%) $(n=114)$ \\
\hline Sensitivity & 89.7 & 77.8 & 97.8 \\
Specificity & 100 & 96.7 & 95.2 \\
Positive predictive value & 100 & 82.4 & 98.9 \\
Negative predictive value & 91.7 & 95.7 & 90.9 \\
Diagnostic accuracy & 95.2 & 93.6 & 97.4 \\
\hline
\end{tabular}

ENT-US: ultrasound guided fine-needle aspiration conducted by an otolaryngologist, ENT-palpation: palpation guided fine-needle aspiration conducted by an otolaryngologist, RD-US: ultrasound guided fine-needle aspiration conducted by a radiologist 
Table 5. Organ distribution in each group, underwent excisional biopsy

\begin{tabular}{lccc}
\hline & ENT-US $(\%)(n=62)$ & ENT-palpation $(\%)(n=110)$ & RD-US (\%) $(n=114)$ \\
\hline Thyroid & $29.0(18)$ & $0.9(1)$ & $55.3(63)$ \\
Salivary gland & $29.0(18)$ & $35.5(39)$ & $14.0(16)$ \\
Lymph node & $37.2(23)$ & $40.0(44)$ & $28.1(32)$ \\
Others & $4.8(3)$ & $23.6(26)$ & $2.6(3)$ \\
\hline
\end{tabular}

ENT-US: ultrasound guided fine-needle aspiration conducted by an otolaryngologist, ENT-palpation: palpation guided fine-needle aspiration conducted by an otolaryngologist, RD-US: ultrasound guided fine-needle aspiration conducted by a radiologist

415예였으며, 이 중 benign, suspicious malignancy, malignant 에 해당하는 경우는 286예로 확인되었다. 각 집단별로 민감 도, 특이도, 양성 예측도, 음성 예측도, 그리고 진단 정확도를 조사하였다. 촉진하 이비인후과군의 민감도(77.8\%)가 다른 군에 비해 낮게 관찰되었으며, 초음파 유도하 이비인후과군 (100\%)과 촉진하 이비인후과군의 특이도(96.7\%)가 초음파 유도하 영상의학과군(95.2\%)보다 높은 것을 확인할 수 있었 다. 진단 정확도의 경우, 영상의학과군이 이비인후과 두 집단 의 결과들보다 높게 조사되었다(Table 4). 각 집단의 기관 분 포는 초음파 유도하 이비인후과군은 비교적 골고루 분포한 반면 초음파 유도하 영상의학과군은 상대적으로 갑상선의 비율이 높았다(Table 5).

\section{고 찰}

세침흡인검사는 외래에서 간단하고 안전하게 검사를 시행 할 수 있으며, 검체의 세포학적 분석을 통해 양성 혹은 악성 여 부를 확인할 수 있어서 이비인후과 및 두경부 외과영역에서 진단방법으로 널리 사용되고 있다.,10) 최근 들어 검사를 따로 영상의학과에 의뢰하지 않고, 임상과 의사가 직접 검사를 시 행하는 비중이 증가하고 있는데, 이를 통해 환자가 병원에 내 원하는 횟수를 줄일 수 있어 진단 기간이 단축되고, 이에 따 른 경제적인 비용 감소 효과도 있다.,4,6) 또한 해부학적 구조 에 익숙한 임상의가 환자의 문진내용이나 이학적 검사를 바 탕으로 원하는 부위에 직접 세침흡인검사를 할 수 있다는 것 이 장점이라 할 수 있겠다. ${ }^{5,6,8,11}$

검사결과는 병리학적 분석을 통해 확인하게 되는데, 검체 의 비적절성으로 인해 종종 비진단적 결과를 얻게 된다. 이 는 검사 도중 목표 부위에 제대로 바늘이 접근하지 못했거나 검사 대상이 낭성(cyst)이라서 적절한 세포를 얻지 못했을 가 능성, 검체 채취 후 슬라이드 글라스에 도말하고 고정하는 과 정에서 손실이 있었을 가능성, 혈액이나 기타 물질에 의해 오염 되어 제대로 관찰이 어려운 경우 등을 생각해 볼 수 있다. ${ }^{12)}$ 본 연구에서는 조직학적 검사결과 unsatisfactory에 해당하는 검 사결과를 비적절한 검체로 분류하였다. ${ }^{13,14)}$

본 연구에서 세침흡인검사 검체의 적절성을 조사한 결과,
이비인후과에서 시행한 결과(ENT-US 87.9\%, ENT-Palpation 87.1\%)가 영상의학과(RD-US 91.3\%)에 비해 적절성 비율은 낮았지만, 이전의 다른 연구들에서 조사된 임상의가 시행한 세침흡인검사에서 검체의 적절성 결과(81.2 92.9\%)와 비교 시 유사한 결과를 보이고 유사한 범주 내에 있는 결과를 볼 수 있었다. 1,4,6,7) 조사결과에 대해서 여러 원인들을 고찰해 볼 수 있는데, 영상의학과의 경우 오랜 임상경험을 지닌 한 명의 술자가 지속적으로 검사를 시행한 것에 비해, 이비인후과에 서는 전공의를 포함한 비교적 시술 경험이 적은 여러 명의 술 자가 검사를 시행한 데에서 오는 차이가 가장 큰 원인으로 생 각된다. Ahn 등 ${ }^{8}$ 의 연구에서 한 명의 술자가 최소 100 회 이상 의 세침흡인검사를 시행했을 때 능숙하게 시술이 이루어지고, 안정된 검체의 적절성을 확보할 수 있다는 의견을 제시하였다.

세침흡인검사결과의 연도별 분포를 보면 저자들의 진료실 에 초음파기기가 보급되고, 진료실 내에서 세침흡인검사를 시 행하는 빈도가 점차 증가하면서, 상대적으로 영상의학과에 의뢰하여 검사를 시행하는 비중이 감소한 것을 확인할 수 있 으며, 최근 3년(2013 2015년도) 간의 결과를 바탕으로 집단 간 검체의 비적절성 비율을 비교했을 때에는 전체 조사 기간 동안의 결과와 달리 유의할 만한 차이를 보이지 않았다. 이를 통해 이비인후과에서도 세침흡인검사와 초음파 사용에 대한 체계적인 수련과 반복된 시술 경험을 통해서 충분히 성공적인 결과를 얻을 수 있을 것으로 기대한다.

검체의 비적절성 비율은 부위에 따라 다양한 차이를 보였 는데 그 중 갑상선에서 검체의 비적절성 비율이 다른 부위에 비해 높음을 확인할 수 있었다.

이는 영상의에 의한 갑상선 초음파의 경우 경험 많은 한 사 람의 임상의에 의해 시행되었고 이비인후과의 경우 경험 많은 임상의뿐만 아니라 상대적으로 경험이 적은 전공의, 전임의를 포함하에 시행되었다. 그리고 심부장기라는 갑상선의 특성 및 근육 내 장기로서 세침흡인검사를 시행하려는 대상이 외 부에서 촉지되지 않고 깊게 위치한 경우가 많으며, 또한 내부 에 낭성 변화를 동반하는 경우도 있어서 이로 인해 정확도가 감소했을 가능성을 생각할 수 있다. 또한 낭성 변화가 동반된 경우, 낭을 둘러싸는 석회화 소견(rim calcification)이 검체 의 비적절성을 증가시키는 요인이 될 수 있다는 결과가 다른 
연구에서 보고되었다.8,12,15)

각 집단별 진단 정확도를 조사한 결과에서 초음파 유도하 이비인후과군(95.2\%)과 촉진하 이비인후과군(93.6\%) 모두, 초음파 유도하 영상의학과군의 결과(97.4\%)보다 낮았지만, 2008년 Tandon 등9)이 시행한 세침흡인검사의 메타분석연구 에서 조사된 결과(민감도 $89.6 \%$, 특이도 $96.5 \%$, 진단 정확도 93.1\%)와 비교해 보면 유사한 수준이었다.

본 연구를 통해서, 이비인후과 임상의로서 가지는 장점을 확인할 수 있었다. 물론 영상의에 비해 진단 정확도에 있어서 다소 낮은 결과를 보였지만 이전에 시행되었던 다른 연구 결 과와 비교하여 더 나은 결과를 보여주었다. 그러므로 세침흡 인검사를 직접 시행함으로써 빠른 진단 효과를 얻을 수 있을 것으로 생각되며, 초음파기기의 사용을 통해 세침흡인검사의 보조적 역할뿐만 아니라 진단 및 치료 계획을 세우는 일련의 과정에 있어서 효율성을 더욱 높일 수 있을 것으로 기대한다.

\section{REFERENCES}

1) Robitschek J, Straub M, Wirtz E, Klem C, Sniezek J. Diagnostic efficacy of surgeon-performed ultrasound-guided fine needle aspiration: a randomized controlled trial. Otolaryngol Head Neck Surg 2010;142(3):306-9.

2) Cannon CR, Richardson LD, Replogle W, Halloran R. Quantitative evaluation of fine-needle aspiration. Otolaryngol Head Neck Surg 1996;114(3):407-12.

3) Kraft M, Lang F, Mihaescu A, Wolfensberger M. Evaluation of clinician-operated sonography and fine-needle aspiration in the assessment of salivary gland tumours. Clin Otolaryngol 2008;33(1): 18-24.

4) Bhatki AM, Brewer B, Robinson-Smith T, Nikiforov Y, Steward DL. Adequacy of surgeon-performed ultrasound-guided thyroid fine-needle aspiration biopsy. Otolaryngol Head Neck Surg 2008;139(1):27-31.
5) Milas M, Stephen A, Berber E, Wagner K, Miskulin J, Siperstein A. Ultrasonography for the endocrine surgeon: a valuable clinical tool that enhances diagnostic and therapeutic outcomes. Surgery 2005; 138(6):1193-200; discussion 1200-1.

6) Bohacek L, Milas M, Mitchell J, Siperstein A, Berber E. Diagnostic accuracy of surgeon-performed ultrasound-guided fine-needle aspiration of thyroid nodules. Ann Surg Oncol 2012;19(1):45-51.

7) Al-azawi D, Mann GB, Judson RT, Miller JA. Endocrine surgeonperformed US guided thyroid FNAC is accurate and efficient. World J Surg 2012;36(8):1947-52.

8) Ahn D, Kim H, Sohn JH, Choi JH, Na KJ. Surgeon-performed ultrasound-guided fine-needle aspiration cytology of head and neck mass lesions: sampling adequacy and diagnostic accuracy. Ann Surg Oncol 2015;22(4):1360-5.

9) Tandon S, Shahab R, Benton JI, Ghosh SK, Sheard J, Jones TM. Fine-needle aspiration cytology in a regional head and neck cancer center: comparison with a systematic review and meta-analysis. Head Neck 2008;30(9):1246-52.

10) Zbären P, Schär C, Hotz MA, Loosli $H$. Value of fine-needle aspiration cytology of parotid gland masses. Laryngoscope 2001;111(11 Pt 1): 1989-92.

11) Seiberling KA, Dutra JC, Gunn J. Ultrasound-guided fine needle aspiration biopsy of thyroid nodules performed in the office. Laryngoscope 2008;118(2):228-31.

12) Grani G, Calvanese A, Carbotta G, D’Alessandri M, Nesca A, Bianchini $\mathrm{M}$, et al. Intrinsic factors affecting adequacy of thyroid nodule fine-needle aspiration cytology. Clin Endocrinol (Oxf) 2013; 78(1):141-4.

13) Eun YG, Ryu EW, Shin IH, Kwon KH. Fine needle aspiration for thyroid nodule: clinical application of bethesda classification. Korean J Otorhinolaryngol-Head Neck Surg 2010;53(7):436-40.

14) Abati A. The national cancer institute thyroid FNA State of the Science Conference: “wrapped up". Diagn Cytopathol 2008;36(6): 388-9.

15) Kelly NP, Lim JC, DeJong S, Harmath C, Dudiak C, Wojcik EM. Specimen adequacy and diagnostic specificity of ultrasound-guided fine needle aspirations of nonpalpable thyroid nodules. Diagn Cytopathol 2006;34(3):188-90. 